\begin{tabular}{|c|c|}
\hline Proceeding of the $9^{\text {th }}$ ICEE Conference 3-5 April 2018 & NCA \\
Military Technical College \\
$\begin{array}{c}\text { Kobry El-Kobbah, } \\
\text { Cairo, Egypt }\end{array}$
\end{tabular}

NCA-3

\title{
A Statistical Study on the Parameters Influences the Formation of Starch Nanoparticles through Acid Hydrolysis
}

Fereshteh Bakhtiari $^{1}$, Said Salah Eldin Elnashaie ${ }^{2}$, Firoozeh Danafar ${ }^{1}$, Fahimeh Kamali $^{1}$

\begin{abstract}
:
Starch is a natural, renewable and biodegradable polymer produced by many plants as a source of stored energy. It is the second most abundant biomass material in nature. Starch has a concentric semicrystalline multiscale structure. This structure allows the production of new nano elements through disruption of amorphous domain by acid hydrolysis. Current environmental concerns have turned starch nanoparticles into candidates of growing interest as bio-nanofiller for nanocomposite applications. In this study, the effects of different parameters, while the time of reaction was limited to $1 \mathrm{hr}$, on starch nano particles formation was investigated. A response surface methodology analysis has been undertaken. The average size of starch nanoparticle obtained in this study was $37.76 \mathrm{~nm}$.
\end{abstract}

Keywords:

Nanoparticle, Acid hydrolysis, starch , starch concentration

1) Department of Chemical Engineering, College of Engineering, Shahid Bahonar University of Kerman, 7618891167 Kerman, Iran

2) Chemical and Biological Engineering Department, University of British Columbia (UBC), Vancouver, Canada 


\section{Military Technical College \\ Kobry El-Kobbah, Cairo, Egypt}

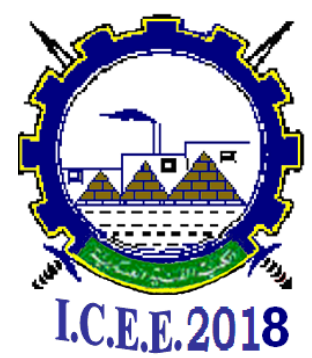

$9^{\text {th }}$ International Conference on

Chemical \& Environmental Engineering

3-5 April 2018

\section{Introduction}

In recent years nanoparticles (NPs) have been investigated for their small size, customized surface, improved solubility and multiple functionality. Starch is one the most studied materials for the usability in food, chemical, textile, papermaking, medicine, reproducibility and cheapness. Starch nanocrystals were used as reinforcing phase in polymer matrix and displayed mechanical improvement properties. Current environmental concerns have led us to use bio degrable materials for nano composite. Starch is a biocompatible, biodegradable and nontoxic polymer that is a semi-crystalline polysaccharide in nature and it is form of granules ranging in size of 2-100 $\mu \mathrm{m}$. Starch is composed of two macromolecular unites, named linear amylase and branches amylopectin. Amylopectin is organized in crystalline clusters of double helices forming stacks of alternating crystalline and amorphous lamellae with a regular repeat distance of 9-10 nm, in which the $\alpha-1,6$-branched branch points reside predominantly in the amorphous lamellae. These are embedded in alternating amorphous and semi-crystalline radial growth rings $100-400 \mathrm{~nm}$ thick. The amorphous rings consist of amylose and amylopectin a disordered conformation, whereas the semi-crystalline rings are formed by the lamellar structure of alternating crystalline and amorphous regions.

\section{Materials and method}

Material: Native wheat starch was prepared. Sulphuric acid (94-98\%) was used after dilution at $3.16 \mathrm{M}$ with distilled water. Chloroform, whatman filter paper was provided.

\subsection{Measurement:}

Particle size analysis: the average size of nanoparticles in emulsion was measured using a Zetasizer (Nano ZS, Malvern instrument). The size range of nanoparticles which is known as the polydispersity index (PdI) can be measured by this instrument.

\subsection{Method of nanostarch preparation:}

Starch nanoparticles was prepared by the method of Angellier et al.(2004). A given weight of wheat starch granules were mixed with $250 \mathrm{ml}$ sulphuric acid solution at a known concentration in a $500 \mathrm{ml}$ Erlenmeyer flask.

The suspension was then stirred at $100 \mathrm{rpm}$ at $40^{\circ} \mathrm{C}$ continuously. In the next step, the suspension was put under ultrasonic treatment at temperature of $40^{\circ} \mathrm{C}$ for different time duration .the final suspension was washed with distilled water using centrifugation until reaching neutral $\mathrm{pH}$. In order to have more uniform distribution size for starch particles, 


\section{Military Technical College \\ Kobry El-Kobbah, Cairo, Egypt}

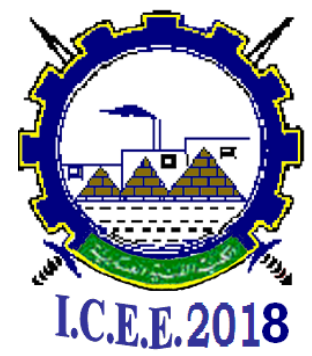

$9^{\text {th }}$ International Conference on

Chemical \& Environmental Engineering

3-5 April 2018

the suspension was passed through a paper filter. finally, chloroform was added to the suspension to avoid microbial growth during its storage.

\section{Results and Discussion}

The effect of four parameters on starch nano particles size was investigated by using response surface methodology. Table 2 depicts the starch concentration, acid concentration, ultrasonic treatment and temperature effect on the particle size of starch nanoparticles.

\subsection{Effect of ultrasonic treatment}

Starch nanoparticles are produced through acid hydrolysis but obtained starch nanoparticles may have tendency to aggregate that willingly sediment. To slow down aggregation, ultrasonic treatment was applied to the starch suspension. On the other hand, the size of starch nanoparticles were changed by ultrasonic treatment.The overall results have shown that ultrasonic treatment during acid hydrolysis of starch was effective in producing starch nanoparticles. To obtain the maximum yield of starch nanoparticles, ultrasonication at $20 \%$ amplitude for 40 min could be suggested. The maximum yield of starch nanoparticles resulted is only $10.5 \%$ of initial amount of starch.

\subsection{Effect of starch concentration}

The aim of present work was to show the influence of starch concentration on SNP. The starch content in solution was varied from 15 to $40 \mathrm{gr}$ and the average size of obtained starch nanoparticles are presented in table 1 . This table shows that, when the starch content was increased, the particle size increases remarkably. The cross-linking reaction intensity could explain the reason of particle size increasing. Our preliminary work indicated that the cross-linking reaction was closely associated with the concentration of reactant. It has to be mentioned that not only starch content effect particle size, but also influence the yield of starch nano particles production. In this study, the time of reaction was limited to $1 \mathrm{hr}$ so the reaction was completed trough ultrasonic treatment. The variation in the solution viscosity means that the emulsion process requires different level of energy input to create the mini emulsions which eventually results in variation in the size of starch nanoparticles. Differences in size were more pronounced when the emulsion was more diluted. 
Military Technical College

Kobry El-Kobbah,

Cairo, Egypt

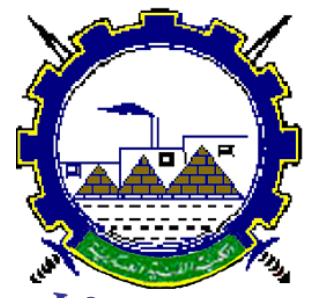

I.C.E.E.2018 $9^{\text {th }}$ International Conference

on

Chemical \& Environmental

Engineering

3-5 April 2018

\subsection{Effect of acid concentration}

The effects of acid concentration on particle size of starch nanoparticles reveal that the increase in the concentration of acid decreases the particle size significantly. The particle size decreases from $127 \mathrm{~nm}$ to $81.9 \mathrm{~nm}$ when the acid concentration increased.

\subsection{Effect of temperature:}

The effect of temperature on the particle size was investigated by varying the temperature of reaction from 25 to $40^{\circ} \mathrm{C}$. As can be seen from table 2 , the temperature had significant influence on final suspension. Hydrolysis temperature was kept low to avoid starch decomposition.

The yields of the starch nanoparticles after acid hydrolysis were calculated as the percent ratio of insoluble particles after centrifuging the hydrolysis dispersion based on the initial dry starch weight.

Where

$$
E=\left(m * \frac{n}{M}\right) * 100
$$

$" m$ " is the mass of starch after filtration

"M" is the initial mass of starch

and " $n$ " is the percentage of particles have diameter below 100nm and determined from DLS analysis. Figure 1 shows the result of DLS analysis for a sample.

\section{Conclusions}

The statistical experimental design used in this study proved that ultrasonic treatment and acid concentration influence the starch particle size in reaction. This is confirmed that starch content has influential effect on production of starch nano particles. We achieved the production aqueous suspensions of starch nanocrystals after 1 day of $3.16 \mathrm{M} \mathrm{H} 2 \mathrm{SO} 4$ hydrolysis at $40^{\circ} \mathrm{C}, 100 \mathrm{rpm}$ and with a starch concentration of $14.69 \mathrm{wt} \%$ with a yield of $10.5 \mathrm{wt} \%$.

\section{References}

[1] Angellier, H., Choisnard, L., Molina-Boisseau, S., Ozil, P., \& Dufresne, A. (2004). Optimization of the preparation of aqueous suspensions of waxy maize starch nanocrystals using a response surface methodology.Biomacromolecules, 5(4), 1545-1551. 
Military Technical College Kobry El-Kobbah, Cairo, Egypt

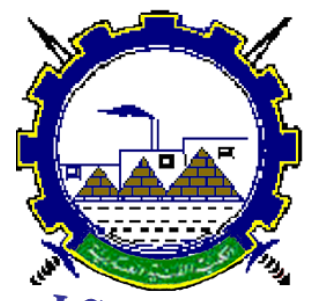

I.C.E.E.2018 $9^{\text {th }}$ International Conference on

Chemical \& Environmental

Engineering

3-5 April 2018

[2] Le Corre, D., Bras, J., Choisnard, L., \& Dufresne, A. (2012). Optimization of the batch preparation of starch nanocrystals to reach daily time-scale.Starch-Stärke, 64(6), 489-496.

[3] Kargarzadeh, H., Ahmad, I., Abdullah, I., Dufresne, A., Zainudin, S. Y., \& Sheltami, R. M. (2012). Effects of hydrolysis conditions on the morphology, crystallinity, and thermal stability of cellulose nanocrystals extracted from kenaf bast fibers. Cellulose, 19(3), 855-866.

[4] 4-Kim, H. Y., Han, J. A., Kweon, D. K., Park, J. D., \& Lim, S. T. (2013). Effect of ultrasonic treatments on nanoparticle preparation of acid-hydrolyzed waxy maize starch. Carbohydrate polymers, 93(2), 582-588.

[5] 5- Le Corre, D., Bras, J., \& Dufresne, A. (2010). Starch nanoparticles: a review.Biomacromolecules, 11(5),1139-1153. 
Military Technical College Kobry El-Kobbah, Cairo, Egypt

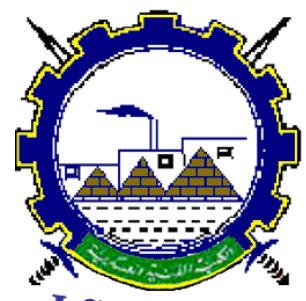

I.C.E.E.2018 $9^{\text {th }}$ International Conference on

Chemical \& Environmental

Engineering

3-5 April 2018

Table1. Setting levels of parameters

\begin{tabular}{|c|c|c|c|c|c|}
\hline Parameter & unit & $\begin{array}{l}\text { Low } \\
\mathrm{xi}=-\end{array}$ & & $\begin{array}{l}\text { Medium level } \\
\mathbf{X}=0\end{array}$ & $\begin{array}{l}\text { High } \\
\text { level }\end{array}$ \\
\hline Temperature & ${ }^{\circ} \mathrm{C}$ & 25 & 35.50 & 40 & \\
\hline $\begin{array}{l}\text { Ultrasonication } \\
\text { duration time }\end{array}$ & $\min$ & 0 & 20 & 40 & \\
\hline $\begin{array}{l}\text { Starch } \\
\text { concentration }\end{array}$ & $\begin{array}{l}\mathrm{g} / 100 \\
\mathrm{~mL}\end{array}$ & 15 & 27.5 & 40 & \\
\hline $\begin{array}{l}\text { Acid } \\
\text { concentration }\end{array}$ & $\mathrm{mol} / \mathrm{L}$ & 3 & 3.75 & 4.50 & \\
\hline
\end{tabular}

Table2: matrix of experiment and results for set of experiment

\begin{tabular}{|c|c|c|c|c|c|c|}
\hline trial & $\begin{array}{c}\text { Ultrasonic } \\
\text { treatment }\end{array}$ & $\begin{array}{c}\text { Starch } \\
\text { Conc. }\end{array}$ & Acid Conc. & $\mathbf{T}\left({ }^{\circ} \mathbf{C}\right)$ & $\begin{array}{c}\text { Size } \\
(\mathbf{n m})\end{array}$ & $\begin{array}{c}\text { Width } \\
\text { size } \\
(\mathbf{n m})\end{array}$ \\
\hline 1 & 0 & 0 & 0 & 0 & 244.0 & 45.2 \\
\hline 2 & 1 & 1 & -1 & -1 & 276.5 & 34.85 \\
\hline 3 & -1 & 1 & -1 & 1 & 321.0 & 127 \\
\hline 4 & -1 & -1 & 1 & 1 & 1012.0 & 221.2 \\
\hline 5 & 1 & -1 & -1 & 1 & 222.0 & 37.76 \\
\hline 6 & -1 & -1 & -1 & -1 & 394.0 & 79.77 \\
\hline 7 & 1 & -1 & 1 & -1 & 453.0 & 48.51 \\
\hline 8 & 1 & 1 & 1 & 1 & 1616.0 & 327 \\
\hline 9 & -1 & 1 & 1 & -1 & 482.0 & 81.95 \\
\hline
\end{tabular}




\begin{tabular}{|l|c|}
\hline Proceeding of the $9^{\text {th }}$ ICEE Conference 3-5 April 2018 & NCA \\
$\begin{array}{c}\text { Military Technical College } \\
\text { Kobry El-Kobbah, } \\
\text { Cairo, Egypt }\end{array}$ & $\begin{array}{c}\text { Chemical \& Environmental } \\
\text { Enginering }\end{array}$ \\
I.C.E.E.2018 & 3-5 April 2018 \\
\hline
\end{tabular}

\section{Size Distribution by Intensity}

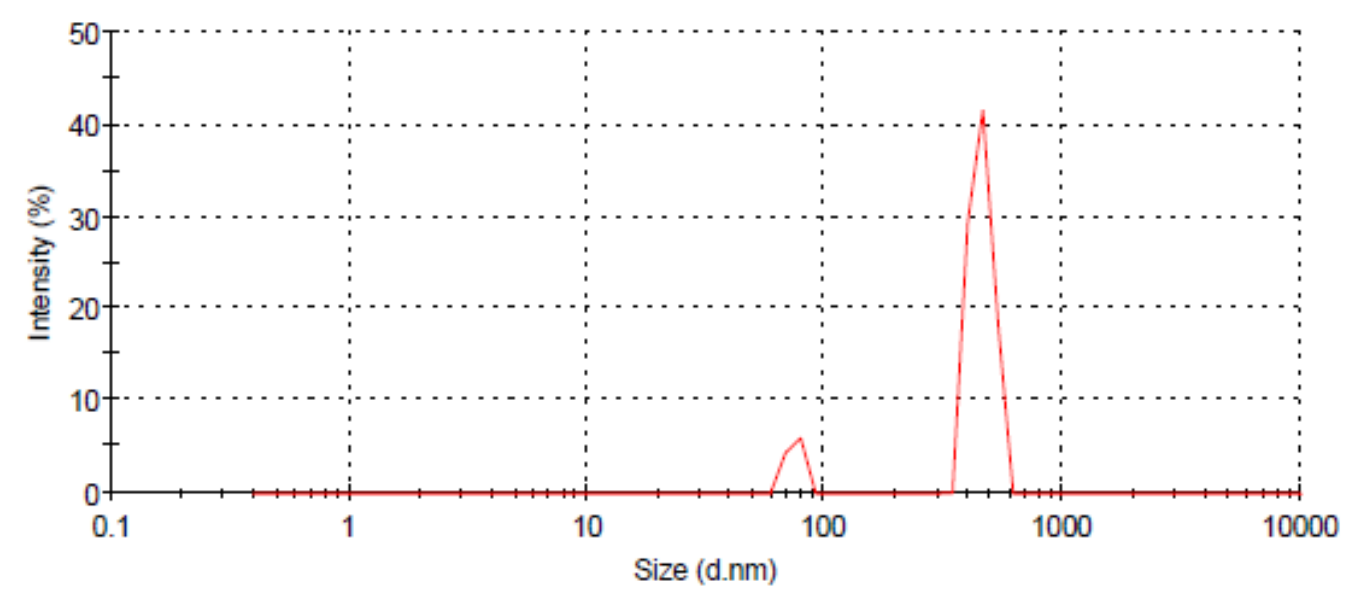

Fig.1: Intensity of starch nanoparticles vs size distribution 